\title{
Evidence for Involvement of the cGMP-Protein Kinase G Signaling System in the Induction of Long-Term Depression, But Not Long-Term Potentiation, in the Dentate Gyrus In Vitro
}

\author{
Jianqun Wu, ${ }^{1}$ Yue Wang, ${ }^{1}$ Michael J. Rowan, ${ }^{2}$ and Roger Anwyl ${ }^{1}$ \\ Departments of ${ }^{1}$ Physiology and ${ }^{2}$ Pharmacology and Therapeutics, Trinity College, Dublin 2, Ireland
}

The involvement of the cGMP-protein kinase G (PKG) signaling pathway in the induction of long-term depression (LTD) and long-term potentiation (LTP) was investigated in the medial perforant path of the dentate gyrus in vitro. Low-frequency stimulation (LFS)-induced LTD of field EPSPs was inhibited by bath perfusion of the selective soluble guanylyl cyclase inhibitor $1 \mathrm{H}-[1,2,4]$ oxadiazolo[4,3,-a]quinoxalin-1-one (ODQ). LFSinduced LTD of EPSPs and whole-cell patch-clamped EPSCs was also blocked by bath perfusion and postsynaptic intracellular injection, respectively, of the selective PKG inhibitor KT5823. Elevation of intracellular cGMP by perfusion of the cGMP phosphodiesterase inhibitor zaprinast resulted in induction of LTD of field EPSPs and EPSCs. Occlusion experiments showed mutual inhibition between LFS-induced LTD and zaprinast-induced LTD. The zaprinast-induced LTD of field

Considerable evidence now exists for a role of the diffusible molecule nitric oxide (NO) as an intercellular messenger in the CNS (Schumann and Madison, 1994; Garthwaite and Boulton, 1995). NO has been proposed to act as an intercellular messenger in the induction of synaptic plasticity, including long-term potentiation (LTP) and long-term depression (LTD), in the hippocampus. A role of NO in LTP induction has been proposed from several lines of evidence. These include the ability of nitric oxide synthase (NOS) inhibitors, or agents which bind NO, to block the induction of LTP in CA1 (Bohme et al., 1991; O'Dell et al., 1991; Schumann and Madison, 1991; Bon et al., 1992; Haley et al., 1992; Doyle et al., 1996) and dentate gyrus (Wu et al., 1997), of NO donors to induce LTP in CA1 (Bohme et al., 1991), of endothelial (e) and neuronal (n) NOS knockout mice to have reduced LTP in CA1 (Son et al., 1996), and also of adenovirus-mediated inhibition and rescue of eNOS to have reduced or normal LTP respectively in CA1 stratum radiatum (Kantor et al., 1996). Recent evidence suggests that NO may be particularly important in regulating the threshold of LTP induction, because NOS inhibitors blocked LTP induced by weak, but not strong, afferent stimulation in CA1 (Chetkovitch et al., 1993; Haley et al., 1993; O'Dell et al., 1994; Malen and Chapman, 1997), and NO (Zhuo et al., 1993, 1994a) or NO donors (Malen and Chapman, 1997) lowered the threshold for LTP induction in CA1. There is also evidence that NO participates in the induction of LTD. In CA1,

\footnotetext{
Received Dec. 11, 1997; revised March 3, 1998; accepted March 5, 1998.

This work was supported by grants from the Health Research Board, Ireland, the Wellcome Trust, and the European Union.

Correspondence should be addressed to J. Wu, Department of Physiology, Trinity College, Dublin 2, Ireland.

Copyright (ㄷ) 1998 Society for Neuroscience $\quad 0270-6474 / 98 / 183589-08 \$ 05.00 / 0$
}

EPSPs was inhibited by perfusion of ODQ and KT5823. In addition, zaprinast-induced LTD of EPSCs was inhibited by postsynaptic application of KT5823. Glutamate receptor stimulation, especially that of metabotropic glutamate receptors (mGluRs), was required for zaprinast-induced LTD, because cessation of test stimulation or perfusion with the mGluR antagonist (+)- $\alpha$-methyl-4-carboxyphenylglycine (MCPG) inhibited zaprinast-induced LTD. No inhibitory effect of ODQ or KT5823 on the induction of LTP of EPSPs or EPSCs was found. These data indicate that the cGMP-guanyly cyclase-PKG signaling pathway in the dentate gyrus is essential for induction of LTD, although not of LTP, in the dentate gyrus.

Key words: long-term depression; hippocampus; cGMP; protein kinase G; EPSP; long-term potentiation

NO was found to induce LTD when paired with low-frequency stimulation of $0.25 \mathrm{~Hz}$, a frequency that alone did not induce LTD (Zhuo et al., 1994a). Moreover, NOS inhibitors blocked LTD induction in the CA1 (Izumi and Zorumski, 1995) and the dentate gyrus (Wu et al., 1997).

Two intracellular targets have been proposed to mediate the action of NO in its involvement in the induction of LTP and LTD: soluble guanylase cyclase, resulting in elevation of cGMP and stimulation of PKG (Gartwaite and Boulton, 1995), and ADPribosyltransferase (ADPRT) (Schumann et al., 1994). Several studies have supported the involvement of the former pathway in the induction of LTP. Inhibitors of soluble guanylyl cyclase or of PKG prevented the induction of LTP in CA1 (Zhuo et al., 1994b; Boulton et al., 1995), and cGMP analogs or activators of PKG lowered the threshold for the induction of LTP (Zhuo et al., 1994b; Arancio et al., 1995). One study has also presented evidence for the involvement of ADPRT, with ADPRT activity stimulated by NO, and inhibitors of ADPRT activity, blocking the induction of LTP (Schumann et al., 1994).

In a recent study, we demonstrated an involvement of NO in the induction of LTP and LTD in the dentate gyrus in vitro by showing that NOS inhibitors blocked the induction of LTP and LTD (Wu et al., 1997). To elucidate the intracellular target of the NO, we have investigated the effects of agents acting on the guanylyl cyclase-cGMP-PKG pathway. Our results indicate that the induction of LTD, but not LTP, is dependent on the activation of the guanylyl cyclase-cGMP-PKG pathway.

\section{MATERIALS AND METHODS}

All experiments were performed on transverse slices of the rat hippocampus (weight 40-80 gm). The brains were rapidly re- 
moved after decapitation and placed in cold oxygenated $(95 \%$ $\left.\mathrm{O}_{2} / 5 \% \mathrm{CO}_{2}\right)$ media. Slices were cut at a thickness of $350 \mu \mathrm{m}$ using a Campden vibroslice and placed in a holding vessel containing oxygenated media at room temperature $\left(20-22^{\circ} \mathrm{C}\right)$. The slices were then transferred as required to a submerged recording chamber and superfused continuously at a rate of $8 \mathrm{ml} / \mathrm{min}$ at $32^{\circ} \mathrm{C}$.

The control media contained (in $\mathrm{mm}$ ): $\mathrm{NaCl} 120, \mathrm{KCl} 2.5$, $\mathrm{NaH}_{2} \mathrm{PO}_{4} 1.25, \mathrm{NaHCO}_{3} 26, \mathrm{MgSO}_{4} 2.0, \mathrm{CaCl}_{2} 2.0$, D-glucose 10 . All solutions contained $100 \mu \mathrm{M}$ picrotoxin (Sigma, St. Louis, MO) to block $\mathrm{GABA}_{\mathrm{A}}$-mediated activity. Additional drugs used were D-2-amino-phosphonopentanoate (AP5; Tocris Cookson), 1-(2-trifluoromethyl-phenyl)imidazole (TRIM) (Lancaster Synthesis), zaprinast (Sigma), (+)- $\alpha$-methyl-4-carboxyphenylglycine (MCPG) (Tocris Cookson), 1H-[1,2,4] oxadiazolo[4,3,-a] quinoxalin-1-one (ODQ) (Tocris Cookson), and KT5823 (Calbiochem, La Jolla, CA). The patch-clamp electrode, resistance 5-8 $\mathrm{M} \Omega$, contained (in $\mathrm{mM}$ ): potassium gluconate $130, \mathrm{KCl} 10$, EGTA 10, $\mathrm{CaCl}_{2} 1, \mathrm{MgCl}_{2}$ 3, HEPES 20, MgATP 5, NaGTP 0.5, QX 314 5, pH 7.2 (using $\mathrm{KOH}$ ).

Whole-cell recordings from dentate granule cells were made using an Axopatch 1D amplifier (5 kHz low-pass Bessel filter), as described previously (O'Connor et al., 1995). The capacitative current was always cancelled electronically, and the series resistance (15-30 $\mathrm{M} \Omega$, as measured directly from the amplifier) was compensated by $60-70 \%$. The mean input resistance was $295 \pm$ $15 \mathrm{M} \Omega$, and the mean resting potential was $-71 \pm 3 \mathrm{mV}$. The input resistance was monitored continuously, and the recording was terminated if it varied by $>10 \%$. Test EPSCs were recorded at a holding potential of $-70 \mathrm{mV}$ in response to stimulation of the medial perforant path at a control frequency of $0.033 \mathrm{~Hz}$, with the stimulation intensity adjusted to evoke an EPSC that was $\sim 30 \%$ of the maximum amplitude, usually $\sim 50-100$ pA. LTD of EPSCs was evoked by low-frequency stimulation (LFS); 60 stimuli at 1 $\mathrm{Hz}$ were applied at $-40 \mathrm{mV}$. The amplitude of LTD of EPSCs was measured at $25 \mathrm{~min}$ after LFS. LTP of EPSCs was induced either by eight trains of eight stimuli at $200 \mathrm{~Hz}$, intertrain interval $0.5 \mathrm{~Hz}$, under current-clamp conditions, or by a pairing protocol consisting of one train of eight stimuli applied at $0 \mathrm{mV}$ under voltage-clamp conditions. Full experiments were performed, providing that certain criteria were met. These included a resting membrane potential of at least $-65 \mathrm{mV}$, a high input resistance (at least $200 \mathrm{M} \Omega$ ), and a low threshold and steep input-output curve for the EPSCs.

Field EPSPs were recorded at a control test frequency of 0.033 $\mathrm{Hz}$ from the medial perforant path in response to stimulation of this path. In each experiment, an input-output curve (afferent stimulus intensity vs EPSP amplitude) was plotted at the test frequency. For all experiments, the amplitude of the test EPSP was adjusted to one-third of maximum, usually $\sim 1.0-1.2 \mathrm{mV}$. Paired-pulse stimulation was given at $0.017 \mathrm{~Hz}$ with $25 \mathrm{msec}$ intervals. Paired-pulse ratio was calculated as E1/E2 (E1, the amplitude of the first EPSP; E2, the amplitude of the second EPSP) and expressed as a percentage. LTD of field EPSPs was evoked by LFS consisting of 900 stimuli at $1 \mathrm{~Hz}$ for $15 \mathrm{~min}$, with the test stimulation voltage remaining at the same amplitude during the LFS. The LTD of field EPSPs was measured at 60-80 min after LFS or zaprinast perfusion. LTP of field EPSPs was induced by eight trains of eight stimuli at $200 \mathrm{~Hz}$; intertrain interval was $0.2 \mathrm{~Hz}$. Control and experimental slices were routinely taken from the same hippocampus.
Recordings were analyzed using the pClamp6 (Axon Instruments). Values are the mean \pm SEM, and Student's $t$ test was used for statistical comparisons.

\section{RESULTS}

\section{Inhibition of guanylyl cyclase prevents LTD, but not LTP, induction}

ODQ has been shown to be a selective inhibitor of soluble guanylyl cyclase, with half-maximal inhibition of $\sim 100 \mathrm{~nm}$ in the hippocampus (Garthwaite et al., 1995). ODQ has been shown previously to inhibit the induction of both LTP in CA1 (Boulton et al., 1995) and LTD in Purkinje cells of the cerebellum (Boxall and Garthwaite, 1996).

In the present experiments, ODQ was found to inhibit the induction of LTD, but not of LTP. Figure $1 A$ shows that after perfusion with ODQ $(10 \mu \mathrm{M})$ for $1 \mathrm{hr}$, which did not cause a change in the field EPSP, application of LFS (900 stimuli at $1 \mathrm{~Hz}$ ) resulted in a markedly reduced amplitude of LTD of the field EPSP, which measured $6 \pm 5 \%(p<0.01 ; n=7)$ compared with a set of control slices in which LTD measured $36 \pm 4 \%(n=6)$. Short-term depression, at 1 min after the LFS, was also reduced by ODQ, from $32 \pm 3 \%$ in control to $15 \pm 4 \%(p<0.01 ; n=7)$. In contrast, Figure $1 B$ shows that ODQ did not inhibit the induction of LTP of field EPSPs, with high-frequency (HFS)induced LTP measuring $132 \pm 6 \%$ in control and $129 \pm 7 \%$ in slices perfused with ODQ.

\section{Inhibition of PKG prevents induction of LTD but not of LTP}

KT5823 is a selective PKG inhibitor with a $K_{\mathrm{i}}$ of 234 nM (Kase, 1988; Nakanishi, 1989). It has been shown previously to inhibit LTP induction in CA1 (Zhou et al., 1994b) and to inhibit LTD in cerebellum Purkinje cells (Ito and Karochet, 1990; Hartell, 1996).

KT5823 $(10 \mu \mathrm{M})$ was found to inhibit the induction of LTD, but not LTP. Figure $2 A$ shows that after extracellular application of KT5823 for $1 \mathrm{hr}$, LFS-induced LTD of EPSPs was strongly inhibited and measured $5 \pm 3 . \%(p<0.01 ; n=8)$ compared with LTD of $29 \pm 5 \%(n=7)$ in control slices.

The action of KT5823 was also examined in whole-cell patchclamp recordings in which KT5823 was allowed to diff use from the patch pipette into the postsynaptic cell. In a previous study from this laboratory, it has been shown that LTD in the dentate gyrus can be induced by a brief LFS under mildly depolarized conditions (Wang et al., 1997). In control patch-clamp recordings, LTD of EPSCs induced by LFS (60 stimuli at $1 \mathrm{~Hz},-40 \mathrm{mV}$ ) measured $36 \pm 3 \%(n=5)$. However, LTD induction was strongly inhibited in cells loaded with KT5823 (10 $\mu \mathrm{M})$, with LTD measuring $2 \pm 3 \%(n=5 ; p<0.01)$ (Fig. $2 B)$.

LTP induced by HFS was not inhibited by KT5823, either applied to the postsynaptic cell or perfused in the bath. Control LTP of EPSCs induced by HFS consisting of either a series of eight trains of eight stimuli $(200 \mathrm{~Hz})$ under current clamp (Fig. $2 C$ ) or one train of eight stimuli $(200 \mathrm{~Hz})$ at $0 \mathrm{mV}$ (Fig. 2D) induced LTP of $145 \pm 3.7 \%(n=5)$ and $138 \pm 5.4 \%(n=5)$, respectively. In the presence of KT5823 $(10 \mu \mathrm{M})$ in the patch pipette, HFS consisting of eight trains of eight stimuli applied under current clamp (Fig. $2 C$ ) or one train of eight stimuli at 0 $\mathrm{mV}$ (Fig. 2D) resulted in LTP induction measuring $143 \pm 5 \%$ $(n=5)$ and $141 \pm 4 \%(n=5)$, respectively, and the levels of LTP were not significantly different from control. Bath perfusion of KT5823 $(10 \mu \mathrm{M})$ also did not block induction of LTP of field EPSPs. In control slices, LTP induced by HFS measured $146 \pm$ 

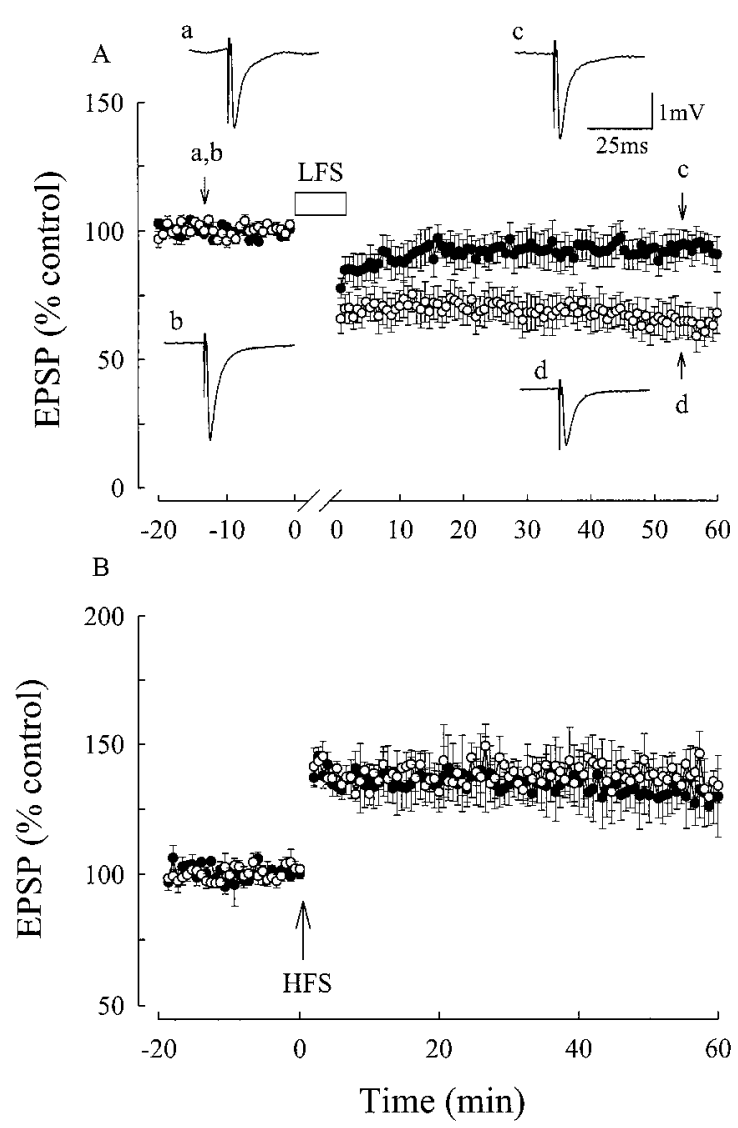

Figure 1. The soluble guanylase inhibitor ODQ prevents the induction of LTD but not of LTP. $A$, In a control set of slices, LFS (900 stimuli, $1 \mathrm{~Hz}$ ) induced LTD of field EPSPs $(\bigcirc) ; n=6$. In a second set of experimental slices, ODQ $(10 \mu \mathrm{M})$ perfused for $1 \mathrm{hr}$ before LFS inhibited the induction of LTD of field EPSPs $(\bullet) ; n=7 . a-d$ show original traces of field EPSPs in control baseline recording $(a, b)$ after induction of LTD in control slices $(d)$ and after block of LTD induction in the presence of ODQ. $B$, In a control set of slices, HFS consisting of eight trains of eight stimuli at $200 \mathrm{~Hz}$ induced LTP of field EPSPs $(\bigcirc)$. In a second set of experimental slices, ODQ perfused for $1 \mathrm{hr}$ before HFS did not inhibit the induction of LTP of field EPSPs $(\bullet)$.

$12 \%$, whereas in slices perfused with KT5823 for $1 \mathrm{hr}$, LTP measured $138 \pm 7 \%(p>0.05 ; n=5)$ (Fig. $2 E)$.

\section{Inhibition of intracellular cGMP breakdown induces LTD}

To investigate the effects of increasing the intracellular level of cGMP, we prevented intracellular cGMP breakdown with the use of the agent zaprinast, which is a selective inhibitor of cGMPspecific phosphodiesterase (Beavo and Reifsnyder, 1990). Zaprinast has been shown previously to induce LTD in Purkinje cells of the cerebellum (Hartell, 1996).

Perfusion of zaprinast $(20 \mu \mathrm{M})$ for $20 \mathrm{~min}$ induced LTD of the field EPSP measuring $27 \pm 4 \%(p<0.01 ; n=10)$ at 80 min after commencement of zaprinast perfusion (Fig. $3 A$ ). Recording of paired-pulse changes during the perfusion of zaprinast showed that the paired-pulse depression present in control (19 $\pm 3 \%$ depression) was reduced during the initial period of perfusion of zaprinast (to $3 \pm 2 \%$ ), indicating that the initial period of depression induced by zaprinast was mediated by a presynaptic decrease in the probability of transmitter release. However, the decrease in paired-pulse depression was transient, and it returned to control value $(18 \pm 3 \%)$ by $40 \mathrm{~min}$ after perfusion of zaprinast was started, although LTD was maintained for $>80 \mathrm{~min}$. Occlusion experiments showed mutual block between the LFS-induced and the zaprinast-induced LTD. First, zaprinast-induced LTD was found to occlude LFS-induced LTD. Thus zaprinast-induced $(20 \mu \mathrm{M})$ LTD measuring $29 \pm 2 \%(n=5)$ resulted in a block of further LTD by LFS $(2 \pm 2 \% ; n=5 ; p<0.001)$ (Fig. 3B). Second, LFS-induced LTD was found to occlude zaprinastinduced LTD. Thus LFS-induced LTD measuring $38 \pm 7 \%$ resulted in a block of further LTD by zaprinast $(3 \pm 2 \% ; n=5$; $p<0.005$ ) (Fig. 3C). These occlusion experiments demonstrate convincingly that the long-lasting depression induced by zaprinast has maintenance mechanisms identical to LFS-induced LTD.

To investigate whether the zaprinast-induced LTD, like the LFS-induced LTD, involved activation of soluble guanylyl cyclase and $\mathrm{PKG}$, zaprinast was applied in the presence of the inhibitor of soluble guanylyl cyclase ODQ $(10 \mu \mathrm{M})$ or the PKG inhibitor KT5823 $(10 \mu \mathrm{M})$. After perfusion of ODQ or KT5823 for $1 \mathrm{hr}$, zaprinast induced a short-term depression, but LTD was strongly inhibited. In ODQ, zaprinast-induced LTD measured $5 \pm 5 \%$ $(p<0.01 ; n=5)$ (Fig. $4 A)$, and in KT5823, zaprinast induced a small potentiation rather than LTD (to $107 \pm 7 \% ; p<0.01 ; n=$ 7) (Fig. 4B). Short-term depression at $1 \mathrm{~min}$ after washout of zaprinast was not inhibited by ODQ $(33 \pm 4 \%$ in control vs $30 \pm$ $3 \%$ in ODQ) but was reduced in KT5823 (17 $\pm 2 \% ; p<0.05 ; n=$ 7). KT5823 applied postsynaptically (10 $\mu \mathrm{M}$ in the patch pipette) also blocked LTD induction. In control experiments, zaprinast induced LTD measuring $36 \pm 3 \%(n=5)$ (Fig. 4C). In cells loaded with KT5823, zaprinast-induced LTD was strongly inhibited, measuring $2 \pm 3 \%(p<0.01 ; n=5)$. Simultaneous measurements of the field EPSP were made in three experiments in which the cell was loaded with KT5823. Zaprinast induced LTD of the field EPSP at a level similar to that found previously, although LTD induction of the EPSC was blocked (Fig. 4D).

\section{Activation of mGluRs is required for zaprinast-induced LTD}

To identify the receptor involved in the zaprinast-induced LTD, experiments were performed involving application of zaprinast in the presence of inhibitors of NMDA receptor (NMDAR) and $\mathrm{mGluR}$ and also with cessation of test stimuli during zaprinast application. Cessation of test stimuli during zaprinast application resulted in an inhibition of LTD induction ( $\pm 3 \% ; n=5 ; p>$ 0.05 ) at $80 \mathrm{~min}$ after zaprinast application (Fig. 5A). The mGluR antagonist MCPG $(500 \mu \mathrm{M})$, perfused for $1 \mathrm{hr}$ before zaprinast application, also prevented LTD induction $(8 \pm 8 \% ; n=5 ; p>$ 0.05 ) at $80 \mathrm{~min}$ after zaprinast application (Fig. $5 B$ ). However, the NMDAR antagonist AP5 did not inhibit LTD induction. After perfusion of AP5 for $1 \mathrm{hr}$, application of zaprinast induced LTD measuring $33 \pm 2 \%(p<0.01 ; n=5)$ (Fig. $5 C)$.

\section{DISCUSSION}

The results of this study present evidence that the induction of LTD in the dentate gyrus involves the soluble guanylyl cyclasecGMP-PKG signaling pathway. The initial step in this intracellular pathway, the production of NO, was shown to be important in LTD induction in the dentate gyrus in a previous study from this laboratory, with the NOS inhibitors TRIM and 3-bromo-7nitro-indazole blocking the induction of LTD (Wu et al., 1997). The involvement of cGMP in LTD induction was demonstrated in the present study by the ability of raised levels of cGMP (by the use of the selective cGMP phosphodiesterase inhibitor zaprinast) to induce LTD, whereas an involvement of soluble guanylyl 

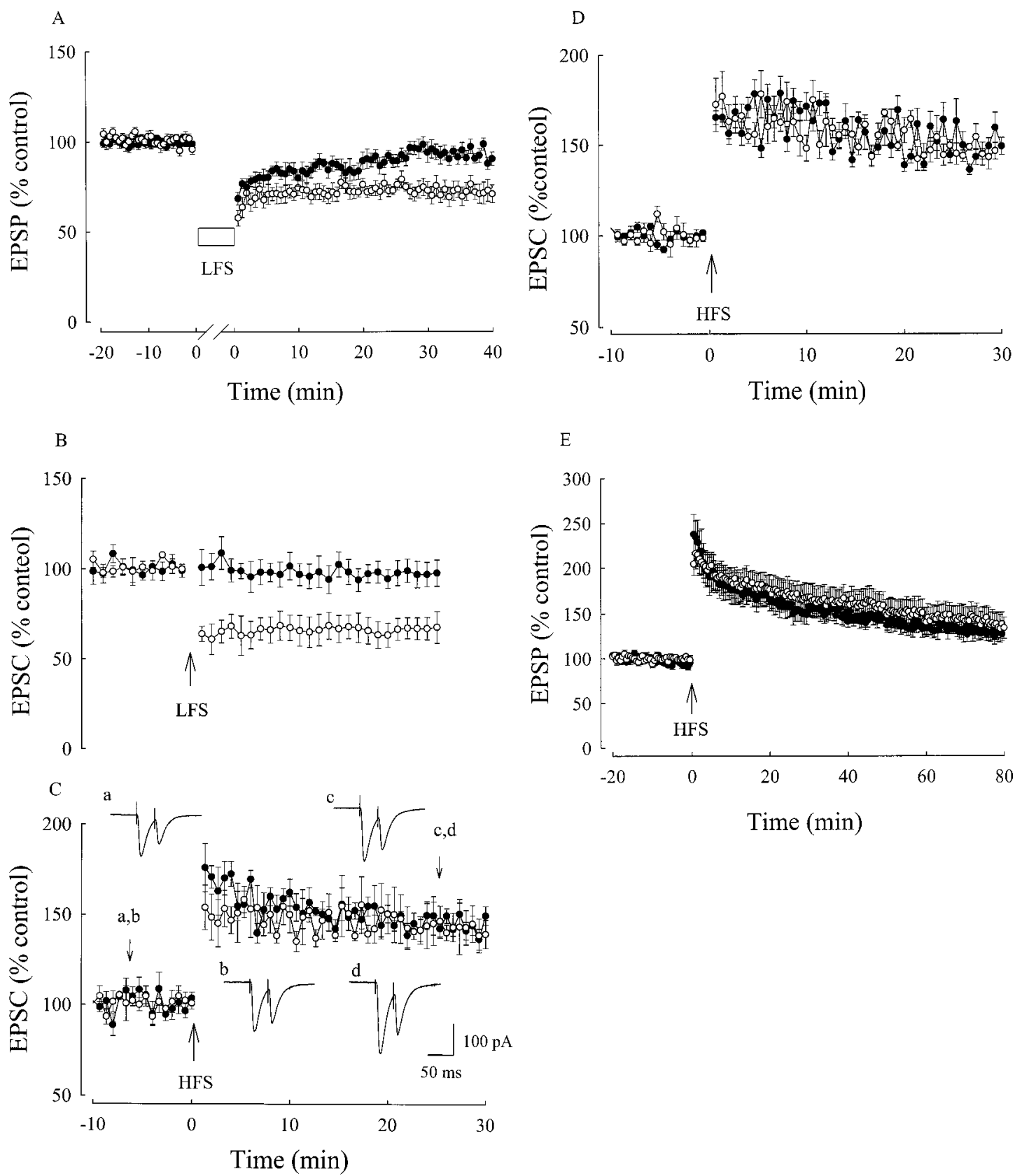

Figure 2. The PKG inhibitor KT5823 $(10 \mu \mathrm{M})$ inhibits the induction of LTD but not of LTP. $A$, In a control set of slices, LFS induced LTD of field EPSPs $(\bigcirc) ; n=7$. In a second set of experimental slices, KT5823 prevented the induction of LTD of field EPSPs $(\bullet) ; n=8$. $B$, In a control set of slices, LFS consisting of 60 stimuli at $1 \mathrm{~Hz}$ applied at $-40 \mathrm{mV}$ induced LTD of EPSCs recorded under whole-cell patch-clamp conditions $(O) ; n=5$. In a second set of experimental slices, LTD of EPSCs was inhibited in cells filled with KT5823 by diff usion from the patch pipette $(\bullet) ; n=5$. $C$, $D$, In control slices, HFS consisting of one train of eight stimuli at $200 \mathrm{~Hz}(C)$ or eight trains of eight stimuli at $200 \mathrm{~Hz}(D)$ induced LTP $(O) ; n=5$. In experimental slices, LTP of EPSCs was not inhibited in cells filled with KT5823 by diffusion from the patch pipette when LTP was induced by one or eight trains of HFS $(C, D)(\mathbf{O}) ; n=5$. The original traces in $C$ show paired-pulse recordings of EPSCs in control baseline recordings $(a, b)$ and after induction of LTP $(c$, d). E, The graph shows that LTP of field EPSPs induced by HFS ( 8 trains of 8 stimuli at $200 \mathrm{~Hz})$ is not blocked by extracellular bath application of KT5823, with the amplitude of LTP induced in control $(\bigcirc)$ not significantly different from that in KT5823 (๑).

cyclase and PKG was demonstrated by ODQ and KT5823, respectively, inhibitors of these messengers, to strongly inhibit LTD induction produced by both LFS and zaprinast. In the CA1 hippocampus, evidence for a role of the cGMP signaling pathway in LTD induction is more debatable. NOS inhibitors were found to block the induction of LTD (Izumi and Zorumski, 1995), and NO directly induced LTD when paired with low-frequency stimulation (Zhuo et al., 1994a) in CA1. In addition, a very recent study has shown that ODQ inhibits LTD induction in CA1 (Gage et al., 1997). However, in other studies in CA1, NOS inhibitors did not prevent LTD induction (Cummings et al., 1994), NO donors were shown to induce only a short-term depression and not LTD (Boulton et al., 1994), and moreover NO donors did not enhance either maximal or weak LTD (Malen and Chapman, 1997). In addition, in CA1, double knockout for nNOS and eNOS did not show significantly reduced LTD (Son et al., 1996), and 

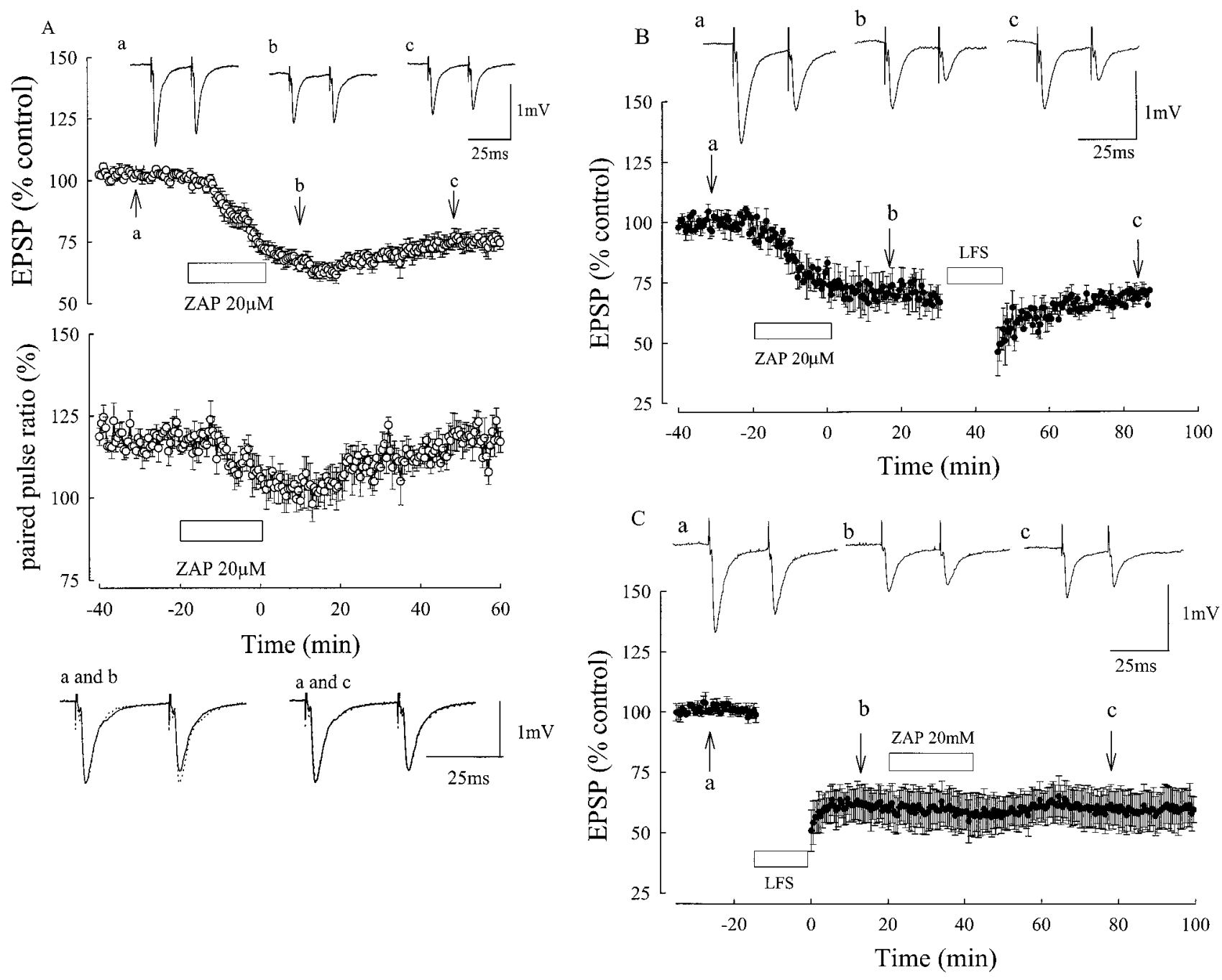

Figure 3. The cGMP phosphodiesterase inhibitor cGMP induces LTD. A, The top graph shows that the perfusion of zaprinast (20 $\mu \mathrm{M}$ for 20 min) resulted in the induction of LTD of the field EPSP; $n=10$. The bottom graph shows that the initial depression lasting $\sim 30$ min was accompanied by a decrease in paired-pulse depression, indicating a presynaptic site of action. However, the remaining LTD was not accompanied by a change in paired-pulse depression. The original traces above the top graph show paired pulse-recordings of EPSPs in control baseline recordings $(a), 10$ min after washout of zaprinast $(b)$ and 50 min after washout of zaprinast $(c)$. The original traces below the bottom graph are the superimposed traces of $a$ and the normalized first EPSP of $b$, showing the early change in paired-pulse depression during the zaprinast perfusion. $a$ and $c$ are $a$ and the normalized first EPSP of $c$, showing the lack of change of paired pulse depression during LTD. $B$, Occlusion experiment showing that after induction of LTD by zaprinast, LFS did not induce further significant LTD; $n=5$. The original traces are paired-pulse recordings of field EPSPs in control baseline recordings $(a)$, 40 min after application of zaprinast $(b)$, and 40 min after LFS $(c)$. $C$, Occlusion experiment showing that after induction of LTD by LFS, zaprinast did not induce further significant LTD; $n=5$. The original traces are paired-pulse recordings of field EPSPs in control baseline recordings $(a)$, 15 min after LFS $(b)$ and 40 min after application of zaprinast $(c)$.

zaprinast induced only a short-term depression (Boulton et al., 1994). We therefore suggest that the NO-cGMP signaling pathway may play a much more prominent role in LTD induction in the dentate gyrus than in CA1, perhaps because of a higher concentration of nNOS in the dentate gyrus than in CA1 (see below).

The involvement of the NO-cGMP signaling pathway in the induction of LTD in the dentate gyrus shows striking similarities with the induction of LTD in Purkinje cells of the cerebellum. There is very strong evidence for the involvement of NO in the induction of Purkinje cell LTD (Garthwaite and Boulton, 1995; Lev-Ram et al., 1997). In addition, induction of LTD in Purkinje cells was blocked by the guanylyl cyclase inhibitor ODQ (Boxall and Garthwaite, 1996) and by PKG inhibitors, including KT5823
(Lev-Ram et al., 1997), and LTD was induced by photorelease of caged cGMP (Lev-Ram et al., 1997) and by zaprinast (Hartell, 1996).

NO has been proposed to act as a retrograde messenger in the induction of LTP in CA1 hippocampus, being released from the postsynaptic cell and then diffusing to the presynaptic terminal for its action in increasing transmitter release (O'Dell et al., 1991; Arancio et al., 1996). In contrast, in the cerebellum, NO has been proposed to act as an anterograde messenger, being released from parallel fiber terminals and diffusing to the Purkinje cell where it mediates LTD (Lev-Ram et al., 1995, 1997). The site of release of NO is likely to be postsynaptic in the hippocampus (O'Dell et al., 1991; Arancio et al., 1996), with NOS being expressed postsynaptically in hippocampal pyramidal and granule cells in the 

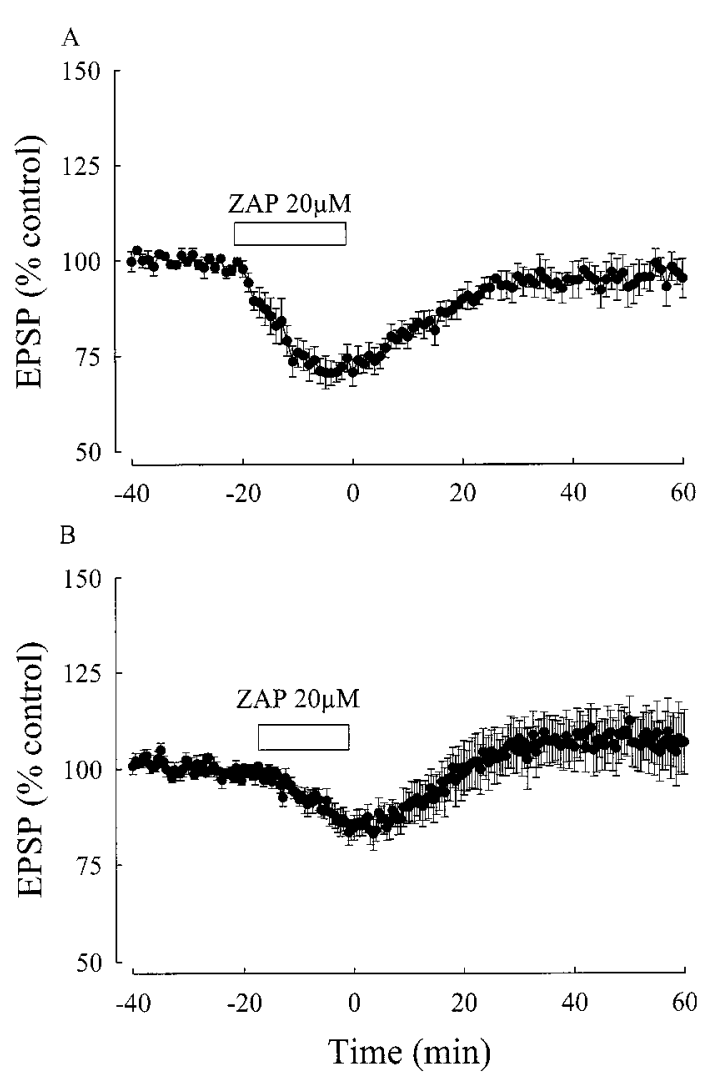
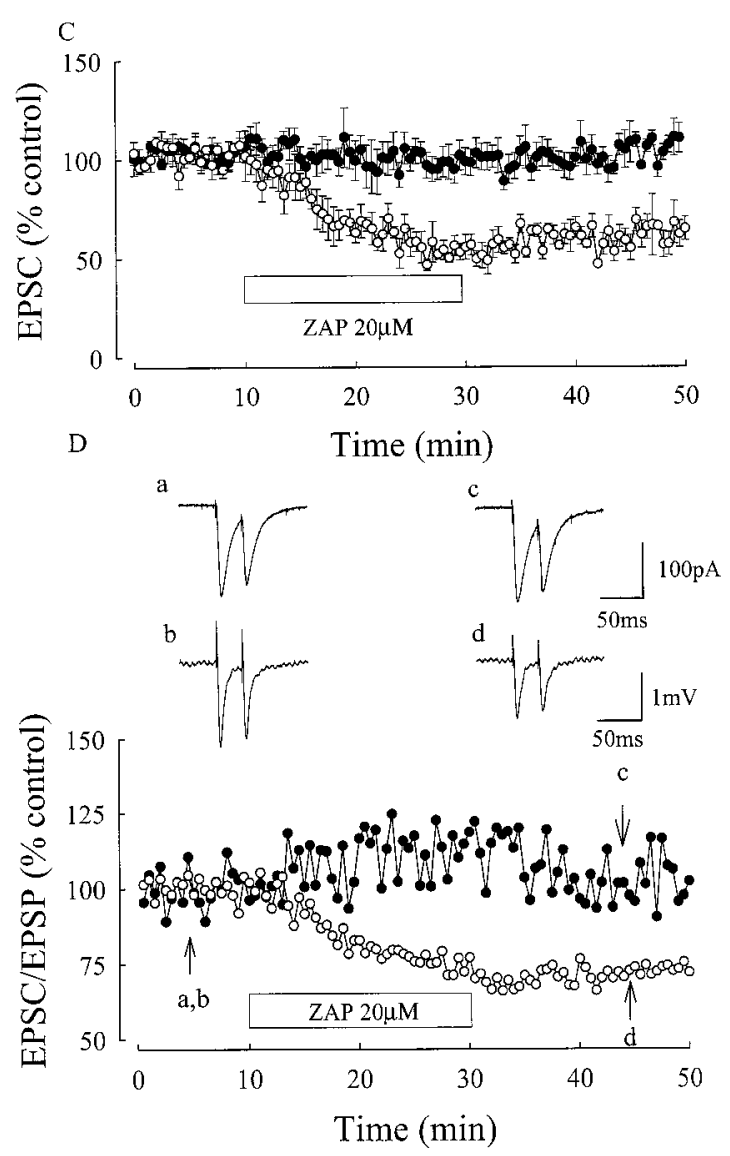

Figure 4. Zaprinast-induced LTD is blocked by the inhibitors of soluble guanylyl cyclase ODQ and PKG inhibitor KT5823. $A$, Perfusion of the soluble guanylyl cyclase inhibitor ODQ $(10 \mu \mathrm{M})$ inhibited the LTD of field EPSPs induced by perfusion of zaprinast $(20 \mu \mathrm{M}) ; n=5$. $B$, Perfusion of the PKG inhibitor KT5823 $(10 \mu \mathrm{M})$ inhibited the LTD induced by perfusion of zaprinast $(20 \mu \mathrm{M}) ; n=7$. $C$, In a set of control experiments, zaprinast (20 $\mu \mathrm{M})$ induced LTD of EPSCs $(\bigcirc)$. In the presence of postsynaptic KT5823 $(10 \mu \mathrm{M}$ in the patch pipette), zaprinast-induced LTD was inhibited $(\bullet)$; $n=5 . D$, An experiment in which the presence of KT5823 in the patch pipette inhibited the zaprinast-induced LTD of EPSCs but did not inhibit the zaprinast-induced LTD of the field EPSP. The original traces show paired-pulse recordings of field EPSPs in control baseline recordings $(a)$ and after perfusion of zaprinast $(c)$, which induced LTD, and also of EPSCs in control baseline recordings and in the postsynaptic presence of KT5823 $(d)$, which blocked the induction of LTD.

mouse, rat, and human dentate gyrus (Dinnerman et al., 1994; Brenman et al., 1996; Hara et al., 1996; Doyle and Slater, 1997; Eliasson et al., 1997). In the present study, postsynaptic application of the PKG inhibitor KT5823 blocked LFS- and zaprinastinduced LTD. This suggests that the PKG is produced postsynaptically, which would be consistent with NO acting as an intercellular postsynaptic messenger in the dentate gyrus, diffusing between adjacent postsynaptic cells in its involvement in mediating LTD. However, the possibility that KT5823 diff used to the presynaptic terminal after its postsynaptic application in the present studies cannot be eliminated. In this case, NO would then act as a retrograde messenger and stimulate presynaptic PKG and subsequently affect transmitter release.

The NO involved in LTD induction in the dentate gyrus may be derived from nNOS, because nNOS shows particularly dense immunohistochemical staining in the dentate gyrus, much higher than in CA1 (Brenman et al., 1996; Eliasson et al., 1997). Moreover, the NOS inhibitor TRIM, which was found to block LTD induction in the dentate gyrus in a previous study ( $\mathrm{Wu}$ et al., 1997), is selective for nNOS. It is of interest that the similarity of the dentate gyrus and the cerebellum regarding LTD induction also applies to the distribution of nNOS, with the molecular and granular layers of the cerebellum having high levels of nNOS (Brenman et al., 1996; Eliasson et al., 1997).

Stimulation at the test frequency was found to be essential for the induction of LTD, and cessation of test stimulation prevented the induction of LTD. Such stimulation may be necessary to activate mGluR, because blocking of mGluR with the antagonist MCPG was found to inhibit the induction of zaprinast-induced LTD. Previous studies from this laboratory have shown that activation of mGluR is essential for the induction of LTD in the dentate gyrus, with the mGluR group I and II antagonist MCPG (O'Mara et al., 1995) and the mGluRII antagonist MCCG (Huang et al., 1997) inhibiting LTD induction, and the mGluR agonist 1S,3R-ACPD directly inducing LTD (O'Mara et al., 1995). mGluR activation is also known to be essential for the induction of cerebellar LTD (Conquet et al., 1994; Hartell, 1994), including zaprinast-induced LTD (Hartell, 1996).

The induction of LTP in the dentate gyrus was found to be prevented by NOS inhibitors in a previous study in this laboratory, demonstrating an involvement of NOS in LTP induction (Wang et al., 1997). However, in this study, LTP induction was not prevented by inhibiting soluble guanylyl cyclase with ODQ or inhibiting PKG with KT5823. These experiments suggest that the 


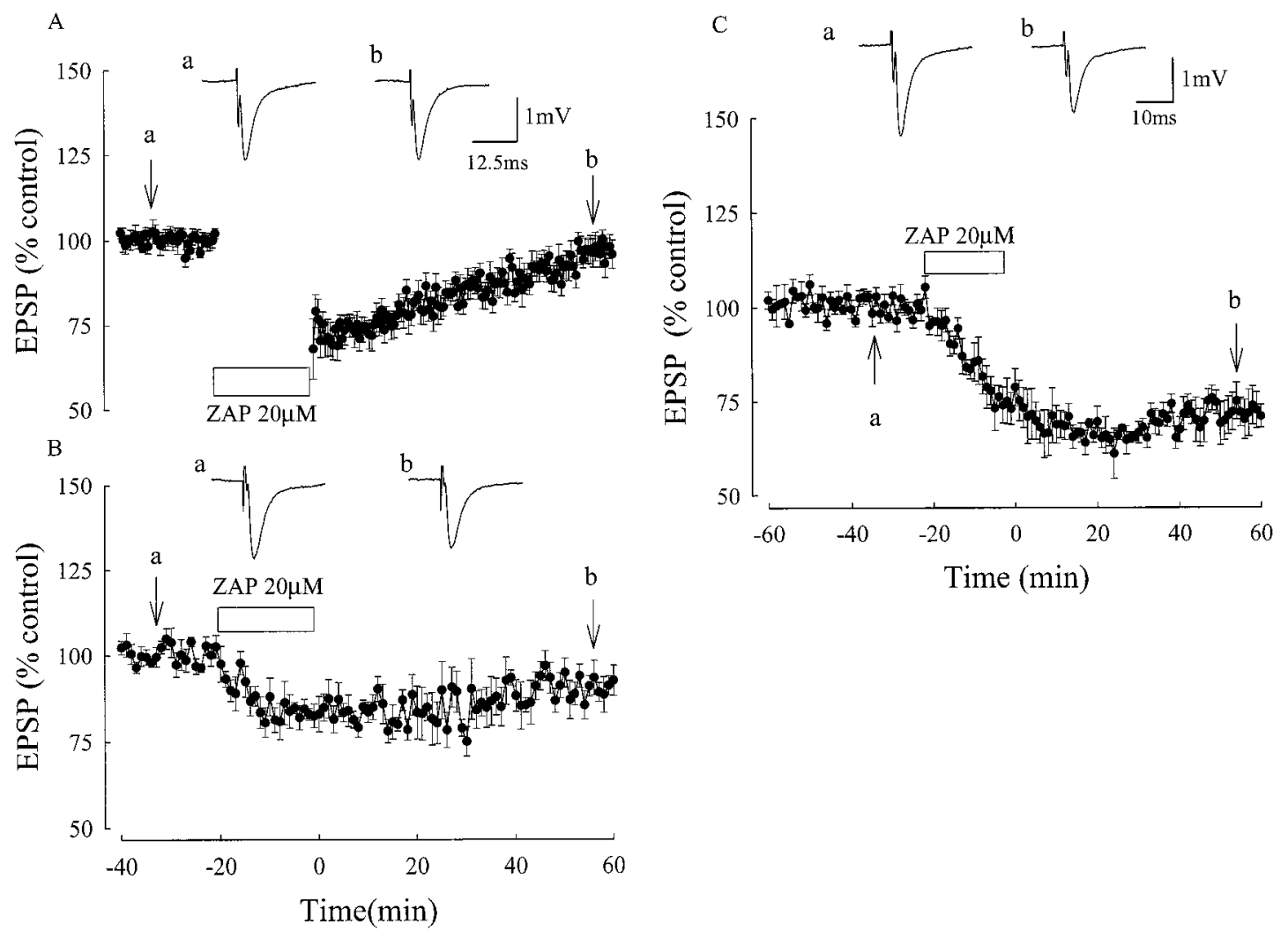

Figure 5. The induction of LTD by zaprinast $(20 \mu \mathrm{M})$ requires test stimulation and activation of mGluRs, but not NMDAR. $A$, Cessation of test stimulation during perfusion of zaprinast significantly reduced the induction of LTD by zaprinast, although not of a short-term depression; $n=5$. The original traces show recordings of EPSPs in control baseline recording $(a)$ and after the induction of LTD by zaprinast $(b)$. $B$, The mGluR antagonist MCPG $(500 \mu \mathrm{M})$ significantly reduced the induction of LTD by zaprinast; $n=5$. The original traces show recordings of EPSPs in control baseline recordings $(a)$ and after the induction of LTD by zaprinast $(b)$. $C$, The NMDAR antagonist AP5 did not significantly prevent LTD induction by zaprinast; $n=5$. The original traces show field EPSPs in the control baseline recording $(a)$ and after the induction of LTD by zaprinast $(b)$.

target site for the action of NO is not the cGMP pathway. A likely alternative target for NO is an ADP ribosyltransferase. It has been proposed previously that an ADP ribosyltransferase is the target of NO in CA1, because NO dramatically increased ADP ribosyltransferase activity in CA1, whereas inhibitors of ADP ribosyltransferase prevented LTP induction (Schumann et al., 1994).

\section{REFERENCES}

Arancio O, Kandel ER, Hawkins RD (1995) Activity-dependent longterm enhancement of transmitter release by presynaptic $3^{\prime}, 5^{\prime}$-cyclic GMP in cultured hippocampal neurons. Nature 376:74-80.

Arancio O, Kiebler M, Lee J, Lev-Ram V, Tsien RY, Kandel ER, Hawkins RD (1996) Nitric oxide acts directly in the presynaptic neuron to produce long-term potentiation in cultured hippocampal neurons. Cell 87:1025-1035.

Beavo JA, Reifsnyder DH (1990) Primary sequence of cyclic nucleotide phosphodiesterase isozymes and the design of selective inhibitors. Trends Pharmacol Sci 11:150-155.

Bohme GA, Bon C, Stutzmann JM, Doble A, Blanchard JC (1991) Possible involvement of nitric oxide in long-term potentiation. Eur $\mathbf{J}$ Pharmacol 199:379-381.

Bon C, Bohme A, Doble A, Blanchard JC (1992) A role for nitric oxide in long-term potentiation. J Neurosci 4:420-424.

Boxall AR, Garthwaite J (1996) Long-term depression in rat cerebellum requires both NO synthase and NO-sensitive guanylyl cyclase. Eur J Neurosci 8:2209-2212.

Boulton CL, Irving AJ, Southam E, Potier B, Garthwaite J, Collingridge GL (1994) The nitric oxide-cyclic GMP pathway and synaptic depression in rat hippocampal slices. Eur J Neurosci 6:1528-1535.

Boulton CL, Southam E, Garthwaite J (1995) Nitric oxide-dependent long-term potentiation is blocked by a specific inhibitor of soluble guanylyl cyclase. Neuroscience 69:699-703.

Brenman JE, Chao DS, Gee SH, McGee AW, Craven SE, Santillano DR, Wu Z, Huang F, Xia H, Peters MF, Froehner SC, Bredt DS (1996) Interaction of nitric oxide synthase with the postsynaptic density protein PSD-95 and $\alpha$-syntrophin mediated by PDZ domains. Cell 84:757-767.

Chetkovitch DM, Klann E, Sweatt JD (1993) Nitric oxide synthaseindependent long-term potentiation in area CA1 of hippocampus. NeuroReport 4:919-922.

Conquet F, Bashir ZA, Davies CH, Daniel H, Feraguti F, Bordi F, Franz-Bacon K, Reggiani A, Matarese V, Conde F, Collingridge GL, Crepel F (1994) Motor deficit and impairment of synaptic plasticity in mice lacing mGluRI. Nature 372:237-243.

Cummings JA, Nicola SM, Malenka RC (1994) Induction in the rat hippocampus of long-term potentiation and long-term depression in the presence of a nitric oxide synthase inhibitor. Neurosci Lett 176:110-114.

Dinnerman JL, Dawson TD, Scell MJ, Snowman A, Snyder SH (1994) Endothelial nitric oxide synthase localized to hippocampal pyramidal cells: implication for synaptic plasticity. Proc Natl Acad Sci USA 91:4214-4218.

Doyle CA, Slater P (1997) Localization of neuronal and endothelial nitric oxide synthase isoforms in human hippocampus. Neuroscience 76:387-395.

Doyle C, Holscher C, Rowan MJ, Anwyl R (1996) The selective neuronal NO synthase inhibitor 7-nitro-indazole blocks both long-term potentiation and depotentiation of field EPSPs in rat hippocampal CA1 in vivo. J Neurosci 16:418-424.

Eliasson MJL, Blackshaw S, Schell MJ, Snyder SH (1997) Neuronal nitric oxide synthase alternatively spliced forms: prominent functional localization in the brain. Proc Natl Acad Sci USA 94:3396-3401. 
Gage AT, Reyes M, Stanton PK (1997) Nitric oxide-guanylyl cyclasedependent and independent components of multiple forms of long-term synaptic depression. Hippocampus 7:286-295.

Garthwaite J, Boulton CL (1995) Nitric oxide signaling in the central nervous system. Annu Rev Physiol 57:683-706.

Garthwaite J, Sotham E, Boulton CL, Neilson EB, Schmidt K, Mayer B (1995) Potent and selective inhibition of nitric oxide-sensitive guanylyl cyclase by $(1 \mathrm{H}-[1,2,4]$ oxadiazolo[4,3,-a]quinoxalin-1-one). Mol Pharmacol 48:184-188.

Haley JE, Wilcox GL, Chapman PF (1992) The role of nitric oxide in hippocampal long-term potentiation. Neuron 8:211-216.

Haley JE, Malen P, Chapman PF (1993) Nitric oxide synthase inhibitors block long-term potentiation induced by weak but not strong tetanic stimulation at physiological brain temperatures in rat hippocampal slices. Neurosci Lett 160:85-88.

Hara H, Waeber PL, Huang PL, Fuji M, Fishman MC, Moskowitz MA (1996) Brain distribution of nitric oxide synthase in neuronal or endothelial nitric oxide synthase mutant mice using [H]L- $N$-nitro-arginine autoradiography. Neuroscience 75:881-890.

Hartell NA (1994) Induction of cerebellar long-term depression requires activation of glutamate metabotropic receptors. NeuroReport 5:913-916.

Hartell NA (1996) Inhibition of cGMP breakdown promotes the induction of cerebellar long-term depression. J Neurosci 16:2881-2890.

Huang LQ, Rowan MJ, Anwyl R (1997) mGluRII agonist inhibition of LTP induction, and mGluRII antagonist inhibition of LTD induction, in the dentate gyrus in vitro. NeuroReport 8:687-693.

Ito M, Karochet L (1990) Receptor subtypes involved in, and time course of, the long-term depression of glutamate receptors in cerebellar Purkinje cells. Neurosci Res 14:27-38.

Izumi Y, Zorumski CFX (1995) Nitric oxide and long-term synaptic depression in the rat hippocampus. NeuroReport 4:1131-1134.

Kantor DB, Lanzrein M, Stary SJ, Sandoval GM, Smith WB, Sullivan BM, Davidson N, Schuman EM (1996) A role for endothelial NO synthase in LTP revealed by adenovirus-mediated inhibition and rescue. Science 274:1744-1748.

Kase H (1988) New inhibitors of protein kinases from microbial source. In: Biology of actinomycetes. Proceedings of Seventh International Symposium on Biology of Actinomycetes (Okami Y, Beppu T, Ogawara H, eds), pp 159-164. Tokyo: Japan Scientific Societies.

Lev-Ram V, Makings LR, Keitz PF, Kao JP, Tsien RY (1995) Longterm depression in cerebellar Purkinje neurons results from coincidence of nitric oxide and depolarization-induced $\mathrm{Ca}$ transients. Neuron 15:408-414.

Lev-Ram V, Jiang T, Wood J, Lawrence DS, Tsien RY (1997) Synergies and coincidence requirements between $\mathrm{NO}$, cGMP and $\mathrm{Ca}$ in the induction of cerebellar long-term depression. Neuron 18:1025-1038.

Malen PL, Chapman PF (1997) Nitric oxide facilitates long-term potentiation, but not long-term depression. J Neurosci 17:2645-2651.
Nakanishi S (1989) K-252-derivatives K252a, K252b, KT5720, KT5962, KT5823. Seitaino-Kagaku 40:364-365.

O'Connor JJ, Rowan MJ, Anwyl R (1995) Tetanically induced LTP involves a similar increase in the AMPA and NMDA receptor components of the excitatory postsynaptic current: investigations of the involvement of mGlu receptors. J Neurosci 15:2013-2020.

O'Dell TJ, Hawkins RD, Kandel ER, Arancio O (1991) Tests of the roles of two diffusible substances in long-term potentiation: evidence for nitric oxide as a possible retrograde messenger. Proc Natl Acad Sci USA 88:11285-11289.

O’Dell TJ, Huang PL, Danwson TM, Dinerman JL, Snyder SH, Kandel ER, Fishman MC (1994) Endothelial NOS and the blockade of LTP by NOS inhibitors in mice lacking neuronal NOS. Science 265:542-546.

O'Mara SM, Rowan MJ, Anwyl R (1995) Metabotropic glutamate receptor-induced long-term depression and depotentiation in the dentate gyrus of the rat hippocampus in vitro. Neuropharmacology 34:983-989.

Schumann EM, Madison DV (1991) A requirement for the intercellular messenger nitric oxide in long-term potentiation. Science 254:15031506.

Schumann EM, Madison DV (1994) Nitric oxide and synaptic function. Annu Rev Neurosci 17:153-183.

Schumann EM, Meffert MK, Schulman H, Madison DV (1994) An ADP-ribosyltransferase as a potential target for nitric oxide action in hippocampal long-term potentiation. Proc Natl Acad Sci USA 91:11958-11962.

Son H, Hawkins RD, Martin K, Kiebler M, Huang PL, Fishman MC, Kandel ER (1996) Long-term potentiation is reduced in mice that are doubly mutant in endothelial and neuronal nitric oxide synthase. Cell 87:1015-1023.

Wang Y, Rowan MJ, Anwyl R (1997) Induction of LTD is NMDARindependent, but dependent on $\mathrm{Ca}$ influx via low voltage activated $\mathrm{Ca}$ channels and release of $\mathrm{Ca}$ from intracellular stores in the dentate gyrus in vitro. J Neurophysiol 77:812-825.

Wu J, Wang Y, Rowan MJ, Anwyl R (1997) Evidence for involvement of the neuronal isoform of nitric oxide synthase during induction of long-term potentiation and long-term depression in the rat dentate gyrus in vitro. Neuroscience 78:393-398.

Zhuo M, Small SA, Kandel ER, Hawkins RD (1993) Nitric oxide and carbon monoxide produce activity-dependent long-term synaptic enhancement in hippocampus. Science 260:1946-1950.

Zhou M, Kandel ER, Hawkins RD (1994a) Nitric oxide and cGMP can produce either synaptic depression or potentiation depending on the frequency of presynaptic stimulation in the hippocampus. NeuroReport 5:1033-1036.

Zhuo M, Hu Y, Schultz C, Kandel ER, Hawkins RD (1994b) Role of guanylyl cyclase and cGMP-dependent protein kinase in long-term potentiation. Nature 368:635-639. 